\title{
Improvement of microbiological quality, antioxidant content and shelf life of jujube (Ziziphus mauritiana cv. BAU Kul) fruit by gamma irradiation
}

\author{
Farzana Mridha ${ }^{\mathrm{a}}$, Roksana Huque ${ }^{\mathrm{b}}$, Mst. Afifa Khatun ${ }^{\mathrm{b}}$, Mahfuza Islam ${ }^{\mathrm{b}}$, Arzina Hossain ${ }^{\mathrm{b}}$, Afzal \\ Hossain $^{\mathrm{b}}$, Md. Shahinur Kabir ${ }^{\mathrm{a}^{*}}$ \\ aDepartment of Botany, Jahangirnagar University, Savar, Dhaka 1342, Bangladesh \\ ${ }^{b}$ Food Technology Division, Institute of Food and Radiation Biology, Atomic Energy Research Establishment, Savar, Dhaka, Bangladesh
}

Received 24th November 2018 / Accepted 21st February 2019

\begin{abstract}
Postharvest loss of inherently perishable fruits is a matter of serious concern for the farmers and traders. Reduction of postharvest loss is one of the key components for ensuring food security. A study was carried out to reduce the postharvest loss of BAU Kul, an improved variety of jujube fruit (Ziziphus mauritiana), by using gamma irradiation. Different doses of gamma irradiation (0.5, 1.0 and 1.5 $\mathrm{kGy}$ ) was applied to the jujube fruit samples and the microbiological quality, antioxidant content and shelf life of those fruits were evaluated. Gamma irradiation initially caused significant reduction of the total heterotrophic bacteria, coliform as well as yeast and mold counts. However, the counts increased in both irradiated and non-irradiated fruit samples with the passage of storage period but the increment was significantly less in the $1.5 \mathrm{kGy}$ irradiated samples. Irradiation played active role in the enhancement of total phenolics and flavonoids contents. The concentration of these antioxidants remained higher in irradiated samples in comparison to non-irradiated control samples throughout the storage period. However, the ascorbic acid content decreased gradually with the increase of radiation dose and storage period. The overall acceptability of the fruit samples was determined by the taste-taking panelist. The irradiated (1.0 and $1.5 \mathrm{kGy}$ ) fruits were acceptable up to 8 days whereas control and $0.5 \mathrm{kGy}$ irradiated fruits lost their acceptability during storage. The study revealed that $1.5 \mathrm{kGy}$ irradiation can improve microbiological quality and extend the shelf life of jujube fruits (cv. BAU Kul) without significant loss of overall antioxidant content and sensory attributes.
\end{abstract}

Keywords: antioxidant markers, gamma irradiation, jujube, microbes, shelf life

\section{INTRODUCTION}

Jujube (Ziriphus mauritiana Lamk.), a member of the family Rhamnaceae, is a fast growing tropical tree and its fruit is a good source of flavonoids, organic acids, vitamins, polysaccharides and microelements ( $\mathrm{Li}$ et al., 2007).This fruit is generally consumed directly as a fresh fruit. Moreover, this fruit is also consumed as dried, candied, pickled and other products like squash or jujube butter. This fruit is used in Chinese system of medicine for spleen diseases and nourishment of blood (Shena et al., 2009). In Bangladesh, jujube (locally called Boroi or Kul) is popular among people of all age groups and usually consumed directly without any processing. BAU Kul, a new variety developed at the germplasm center of Bangladesh Agricultural University (BAU), has

\footnotetext{
*Author for correspondence: Dr. Md. Shahinur Kabir, Department of Botany, Faculty of Biological Sciences, Jahangirnagar University, Savar, Dhaka 1342, Bangladesh. Email-shahin@juniv.edu
} 
gained huge popularity among the available varieties. The demand of this variety is very high all over the country mainly because of its taste, high yield, suitability for cultivation, nutritional value and reasonable price. BAU Kul contains a complex microbial flora including potential plant pathogens and saprophytes. Prevalence of various fungi on jujube fruits is high $(46.86 \%)$ and BAU $\mathrm{Kul}$ was found as the most disease vulnerable variety than other jujube varieties available in Bangladesh (Hoque et al., 2016). Like other jujube fruits, BAU Kul has a short shelf-life of only 4-5 days at ambient temperature. Such a short postharvest shelf-life results huge financial loss for the farmers and traders.

Ionizing radiation of food products is now recognized as a safe and effective technology for improving quality of fruits, vegetables and juices (Kume et al., 2009; Song et al., 2006). Furthermore, no toxic radioactive effect remains on treated foods (Farkas and Mohácsi, 2011). Most of the organization related to food and health safety reported it as an effective technology for the elimination of food spoilage organisms, extension of shelf life of fresh food and reduction of postharvest loss (IAEA,1977; ICGFI, 1998; WHO, 1981). Gamma irradiation is mostly used than other ionizing radiations (e.g., x-rays, electron beam) in food sector. It is widely used as an alternative to chemical fumigants and preservatives which have adverse effects on human health and environment.

Despite of high popularity and productivity of BAU Kul, few studies have been conducted on this variety (Hoque et al., 2016; Talukdar et al., 2014; Tanvir et al., 2015; Uddin and Hussain, 2012) and no published data available to date on the effect of gamma irradiation on the microbiological and biochemical attributes of BAU Kul. Thus, this study was performed to evaluate the effect of gamma irradiation on microbial quality, antioxidant content and shelf life of this variety of jujube during storage at ambient temperature.

\section{MATERIALS AND METHODS}

\section{Sample collection, irradiation and storage.} Jujube fruits (cv. BAU Kul) were procured from local retailers and transported to the laboratory immediately after collection in a clean sterilized container. The samples used in this study were uniform in size, apparently free from any visible insect infestation, mechanical injury or deterioration. Collected fruit samples were put into sterilized perforated low-density polyethylene zipper bags. The packed samples were labeled properly with three selected doses of gamma irradiation (0.5 kGy, $1.0 \mathrm{kGy}$ and $1.5 \mathrm{kGy})$ and a non-irradiated packed sample was kept as control. There were 3 replicates for each treatment and control (non-irradiated). Samples labeled as treated were irradiated in a $50 \mathrm{kCi} \mathrm{Co}{ }^{60}$ gamma irradiator (dose rate $6.4 \mathrm{kGy} / \mathrm{hr}$ ) located at Institute of Food and Radiation Biology, Bangladesh Atomic Energy Research Establishment, Savar, Dhaka, Bangladesh. Both irradiated and control samples were stored at ambient temperature in air. Microbiological, biochemical and sensory attributes of all samples were assessed before gamma irradiation, immediately after irradiation (0 day of storage) and also after 4 and 8 days of storage.

\section{Determination of $\mathrm{pH}$ and moisture content.} An automatic electric $\mathrm{pH}$ meter (JENWAY 3510, $\mathrm{UK}$ ) was used to determine the $\mathrm{pH}$ of the samples. For this purpose, fruit of each sample was separately homogenized in a homogenizer. After adjusting and stabilizing the $\mathrm{pH}$ meter, the $\mathrm{pH}$ was recorded. The moisture content of jujube samples was determined following the method described previously (AOAC, 1975).

Microbiological analysis. For microbiological analysis, standard techniques (Cappuccino and Sherman, 1996; ICMSF, 1978) were used to enumerate bacterial load. Fruit sample (10 g) from each sample was separately homogenized in $90 \mathrm{ml}$ $0.9 \%$ saline solution. Subsequent ten-fold serial dilutions were made and $100 \mu$ diluted sample was spread onto the plate containing appropriate medium (HiMedia). Nutrient agar (NA), MacConkey agar and potato dextrose agar (PDA) were used to enumerate total heterotrophic bacterial count (THBC), total coliform count (TCC) and total yeast mold count (TYMC), respectively. The NA and MacConkey plates were incubated at $37^{\circ} \mathrm{C}$ for 24 hours. The PDA plates were incubated at room temperature for 5 days. 
After incubation, result was recorded by counting the characteristic colonies formed on the plates. The counts, after appropriate calculation, were expressed as colony forming units per gram (cfu/g) of fresh fruit (Mridha et al., 2017).

\section{Total phenolics content and total flavonoids} content. BAU Kul fruit samples of both control (non-irradiated) and irradiated were separately homogenized with $80 \%$ methanol in a homogenizer (Wisetris 20). The homogenate was then centrifuged at $5000 \mathrm{rpm}$ for 10 minutes and the supernatant was filtered through filter paper (Whatman No.1). All the sample extracts (filtrate) were used for subsequent phenolics or flavonoid content determination.

The Folin-Ciocalteu (FC) method was used to determine the total phenolics content (Singleton and Rossi, 1965). Briefly, an aliquot of extract was added to FC reagent (1:10). After few minutes, $7.5 \%$ sodium carbonate solution was added and the volume of the mixture was adjusted to $10 \mathrm{ml}$ with distilled water. The tubes were kept in dark and the absorbance of the solution was measured by a spectrophotometer at $765 \mathrm{~nm}$ (Spectro UVVIS, Labomed). Calculation was done using gallic acid as a standard and results were reported as $\mathrm{mg}$ gallic acid equivalents (mg GAE) per $100 \mathrm{~g}$ of fresh weight.

Total flavonoids (TF) content was determined according to colorimetric method (Chang et al., 2002; Shibata et al., 1975). Briefly, an aliquot of the extract was taken in test tube. One hundred microlitre of $10 \%$ aluminum chloride and $100 \mu \mathrm{l}$ $1 \mathrm{M}$ potassium acetate were added sequentially to the test tube. The volume of the mixture was adjusted to $5 \mathrm{ml}$ by distilled water. The tubes were kept at room temperature for 30 minutes and absorbance of the solution was measured by a spectrophotometer at $415 \mathrm{~nm}$ (Spectro UV-VIS, Labomed). Standard curve was prepared using Quercetin hydrate solution and results were expressed as milligram of quercetin equivalent (mg QE) per $100 \mathrm{~g}$ of fresh fruit.

Ascorbic acid content. Titrimetric method was used to determine the ascorbic acid content (Ranganna, 1986). Two grams of fruit from each sample was homogenized with $25 \mathrm{ml} \mathrm{3 \%}$ metaphosphoric acid and filtered through a filter paper. Then titration was done by 2, 6- dichloroindophenol dye to a pink end-point with $5 \mathrm{ml}$ of filtrate and the results were expressed as mg per $100 \mathrm{~g}$ of fresh sample.

Sensory attributes. Samples were evaluated by a taste testing panelist of ten judges who observed the sensory attributes (color, flavor and texture) from randomly assigned irradiated and nonirradiated samples. They marked the samples on a 9-point Hedonic scale (Krum, 1955) where 0-2 represents extremely dislike, 3-5 dislike, 6-8 acceptable or good and 9 excellent for color, flavor and texture. An overall acceptability was calculated taking average of the three attributes.

Statistical analysis. The data were analyzed and expressed as an average. Significant differences were analyzed by the Student's t-test and considered significant at the level of $p<0.05$.

\section{RESULTS AND DISCUSSION}

The $p H$ and moisture content. The initial average $\mathrm{pH}$ value of jujube sample was $4.81 \pm 0.06$. This $\mathrm{pH}$ value is slightly higher than that of the findings of Uddin and Hussain (2012) who observed $\mathrm{pH} 4.50$ for fresh BAU Kul variety. In another study, $\mathrm{pH}$ value of 4.39 to 4.56 for Tohafy and 4.72 to 4.57 for Balahy varieties of jujube was recorded in 2007 and 2008, respectively (Ezz et al., 2011). No significant changes in $\mathrm{pH}$ values were observed between irradiated and control samples for all the storage treatments (Table 1). Previous studies also revealed that low dose gamma irradiation ( 0.1 to $1.5 \mathrm{kGy}$ ) does not affect the $\mathrm{pH}$ value in strawberry, raspberry and passion fruits (Golding et al., 2015; Majeed et al., 2014; Verde et al., 2013). In the present study, the moisture content of non-irradiated sample was $87.58 \%$. Almost similar level of moisture content was also reported in BAU Kul in two separate studies (Uddin and Hussain, 2012; Talukdar et al., 2014). Moisture content in all irradiated samples was increased immediately (at 0 day) after treatment, but not for storage at 4 day and 8 day (Table 1). This increase may be due to tissue softening by partial degradation of polysaccharides in response to irradiation (D'amour et al., 1993). During storage period, moisture content reduced in all 
experimental samples which might be due to the transpiration.

Microbiological quality. Data on the microbiological quality of gamma-irradiated and non-irradiated jujube fruits is shown in Figures 13. In fresh non-irradiated jujube fruit samples, the average THBC, TYMC and TCC were 5.04 \pm 0.63 $\log \mathrm{cfu} / \mathrm{g}, 4.39 \pm 0.51 \mathrm{log} \mathrm{cfu} / \mathrm{g}$ and $3.20 \pm 0.35 \mathrm{log}$ $\mathrm{cfu} / \mathrm{g}$, respectively. These microorganisms represent both the indigenous microbial flora and contamination during post-harvest handling of the fruits. The total counts were higher than the maximum criterion value set by GCC Standardization Organization (GSO, 2014).

Gamma radiation applied in this study caused the reduction of the THBC, TYMC and TCC in a dose dependent manner but the applied doses did not completely eliminate the microbes present in the fruit samples. The average THBC decreased 1.9logat $1.5 \mathrm{kGy}$ dose immediately after irradiation (Figure 1). Application of gamma radiation at 0.5 and $1.0 \mathrm{kGy}$ doses initially caused 0.24 and $0.81 \log$ reduction of THBC. Highest reduction of TYMC (1.35 log) and TCC (2.09 log) was achieved by the application of $1.5 \mathrm{kGy}$ gamma irradiation while the other two doses $(0.5$ and $1.0 \mathrm{kGy}$ ) caused relatively less reduction of those counts. According to the IGCFI (1998), irradiation with low doses does not kill all the microbes but decrease the total contamination. With the passage of the storage time, THBC, TYMC and TCC increased significantly in the control (non-irradiated) samples. These counts also increased in the irradiated fruits samples but numbers were far below than that of the nonirradiated fruit sample. An increase of the number of microbial loads in $1.0 \mathrm{kGy}$ irradiated fruits of blackberries were also described by Oliveira et al. (2013). However, it is noteworthy to mention that microbial counts of irradiated samples increased in a slow rate than that of non-irradiated sample during storage. The THBC, TCC and TYMC increased significantly in the non-irradiated sample after 8 days of storage at ambient temperature compared to the initial counts obtained immediately after the collection of fruits. In case of THBC, around $1.9 \mathrm{log}$ increase was recorded in the non-irradiated control sample after 8 days of storage while $54.74 \%$ less increase of the heterotrophic bacteria was recorded in 1.5 kGy gamma irradiated samples. The TYMC and TCC of the samples were also decreased significantly immediately after gamma irradiation. Iqtedar et al. (2016) also observed the lowest increase of microbial count in storage after the application of $2 \mathrm{kGy}$ gamma irradiation in apples.

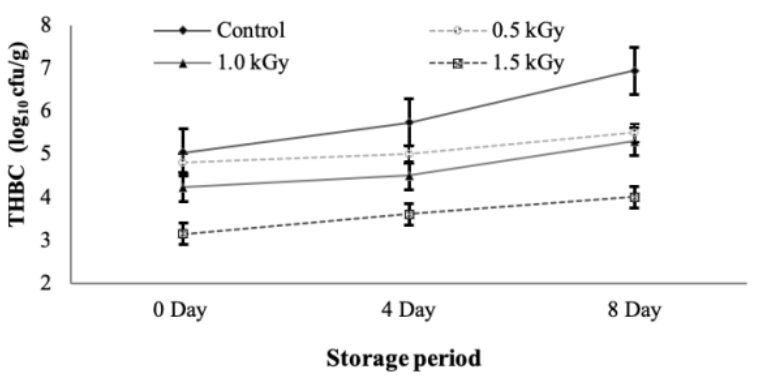

Figure 1. Effect of gamma irradiation on THBC of jujube fruits during storage period.

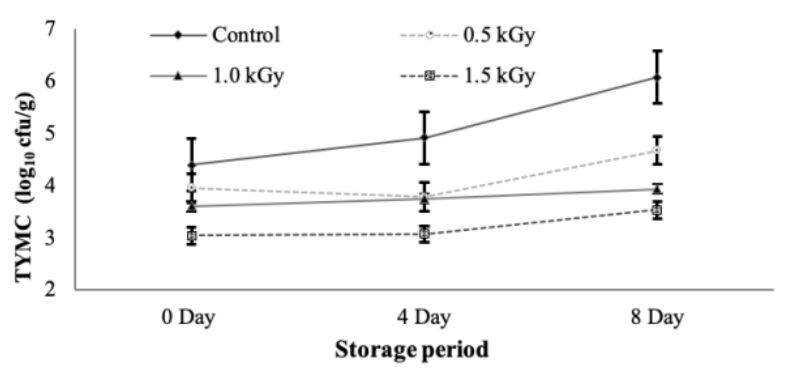

Figure 2. Effect of gamma irradiation on total yeast and mold of jujube fruits during storage.

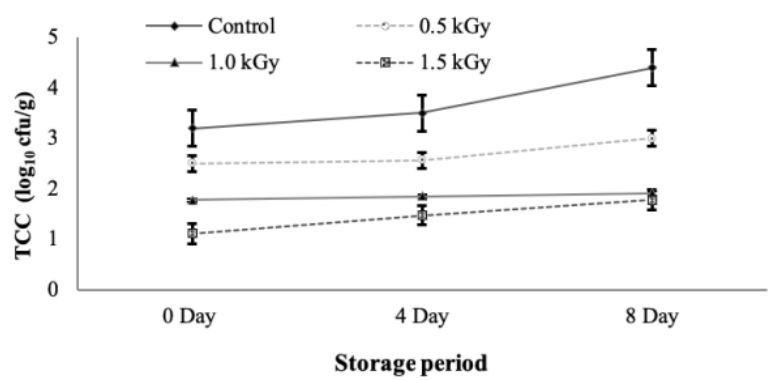

Figure 3. Effect of gamma irradiation on total coliform count of jujube fruits during storage.

Antioxidant content. Ascorbic acid, phenolics and flavonoids present in fruits and vegetables have received attention of the health-conscious persons because of having antioxidant activity. Phenolics are important free radical scavengers and plays significant role to minimize molecular 
damage (Koley et al., 2011).The total phenolics content of BAU Kul was found $44.17 \pm 4.46 \mathrm{mg}$ $\mathrm{GAE} / 100 \mathrm{~g}$ for the control sample. Nearly similar phenolics content $(41.40 \pm 0.2 \mathrm{mg}$ GAE/100g) was also reported in Ziziphus rugosa (Karuppusamy et al., 2011). Application of gamma irradiation increased the phenolics content in treated samples (Figure 4).

Table 1. Effect of gamma irradiation on $\mathrm{pH}$ and moisture content of jujube samples during storage.

\begin{tabular}{ccccccc}
\hline \multirow{2}{*}{ Treatment } & \multicolumn{3}{c}{$\mathbf{p H}$} & \multicolumn{3}{c}{ Moisture Content (\%) } \\
\cline { 2 - 7 } & 0 Day & 4 Day & 8 Day & 0 Day & 4 Day & 8 Day \\
\hline Control & $4.81 \pm 0.06^{\mathrm{a}}$ & $4.84 \pm 0.12^{\mathrm{a}}$ & $4.85 \pm 0.06^{\mathrm{a}}$ & $87.58 \pm 0.54^{\mathrm{a}}$ & $85.60 \pm 0.57^{\mathrm{a}}$ & $82.22 \pm 0.04^{\mathrm{a}}$ \\
$0.5 \mathrm{kGy}$ & $4.83 \pm 0.08^{\mathrm{a}}$ & $4.84 \pm 0.09^{\mathrm{a}}$ & $4.85 \pm 0.01^{\mathrm{a}}$ & $90.50 \pm 0.15^{\mathrm{b}}$ & $85.41 \pm 0.48^{\mathrm{a}}$ & $81.00 \pm 0.05^{\mathrm{b}}$ \\
$1.0 \mathrm{kGy}$ & $4.80 \pm 0.01^{\mathrm{a}}$ & $4.80 \pm 0.07^{\mathrm{a}}$ & $4.82 \pm 0.04^{\mathrm{a}}$ & $89.27 \pm 0.24^{\mathrm{c}}$ & $84.70 \pm 0.31^{\mathrm{b}}$ & $81.61 \pm 1.08^{\mathrm{b}}$ \\
$1.5 \mathrm{kGy}$ & $4.83 \pm 0.03^{\mathrm{a}}$ & $4.81 \pm 0.05^{\mathrm{a}}$ & $4.82 \pm 0.08^{\mathrm{a}}$ & $90.71 \pm 0.20^{\mathrm{c}}$ & $86.19 \pm 1.02^{\mathrm{a}}$ & $82.80 \pm 0.02^{\mathrm{a}}$ \\
\hline
\end{tabular}

Values are the average of 3 replicates. Values with different lowercase letters within a column differ significantly $(p<0.05)$.

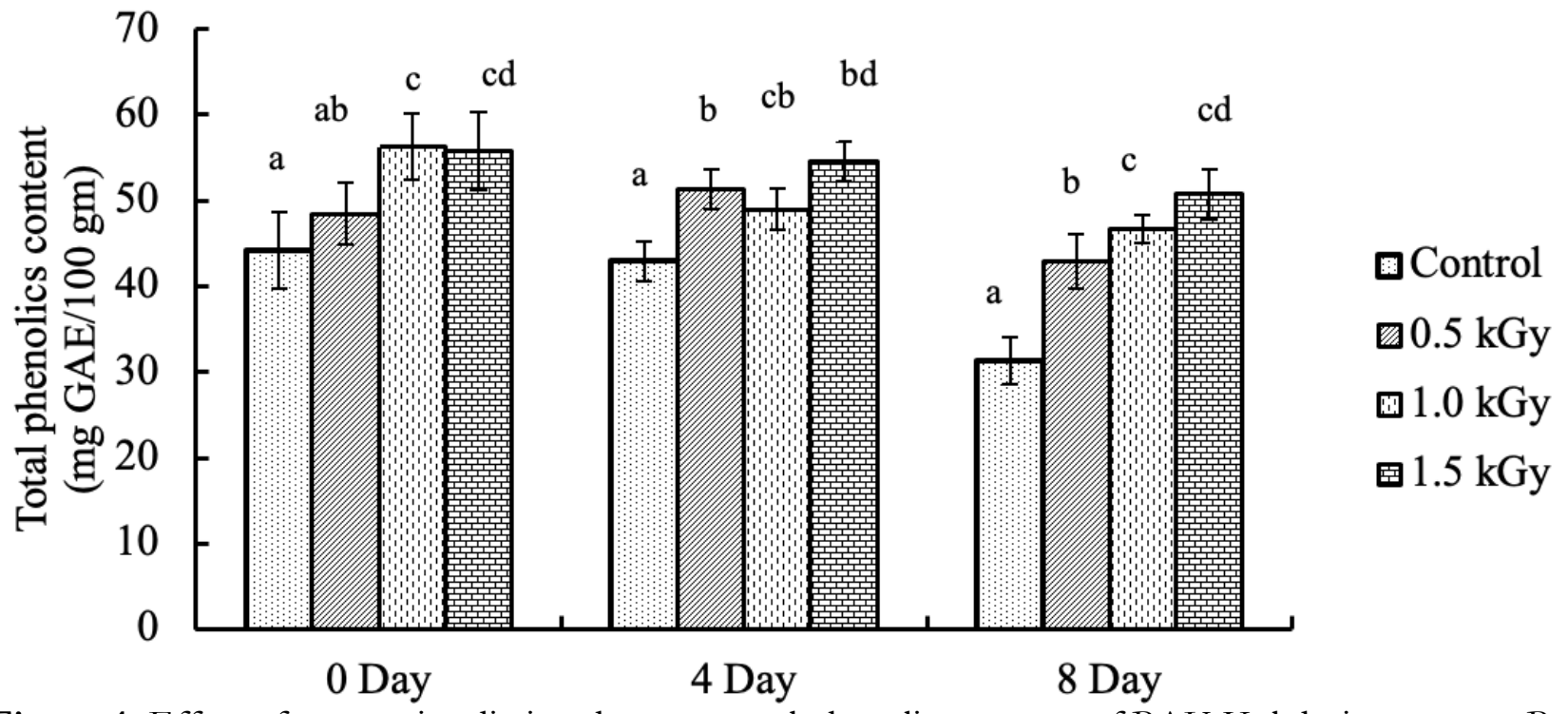

Figure 4. Effect of gamma irradiation doses on total phenolics content of BAU Kul during storage. Bars with different lowercase letters differ significantly $(p<0.05)$.

In this study, significant increase of phenolics content $(27.40 \%)$ was observed in the samples treated with $1.0 \mathrm{kGy}$ gamma irradiation. The observed increase of total phenolics after gamma irradiation may be due to the better extractability of these compounds and decomposition of some insoluble phenolic compounds (Villavicencio et al., 2000). Increased concentration of total phenolics treated with gamma irradiation $(0.25$ and $0.5 \mathrm{kGy}$ ) was also observed in bitter gourd (Khatun et al., 2012). Accumulation of phenolics at high doses of gamma irradiation was also reported in other study (Beltagi et al., 2011).With the passage of storage time, gradual decrease of total phenolics content observed in the non- irradiated sample. After 8 days of storage, $29.08 \%$ reduction of phenolics was observed in the control sample. However, the phenolics content in the gamma irradiated samples remained above the initial concentration found in non-irradiated jujube fruits.

Flavonoids are ubiquitous secondary products among which epicatechin, quercetin, epicatechin gallate are well-known for their antioxidant activity. Antioxidant activities of flavonoids are stronger than those of vitamins $\mathrm{C}$ and phenolic compound because of multiple hydroxyl groups present in their chemicals (Geldof and Engeseth, 2002). The fresh non-irradiated BAU Kul had $15.87 \pm 1.97 \mathrm{mg} \mathrm{QE} / 100 \mathrm{~g}$ of total flavonoids 
which is higher than the value $(10.02 \pm 3.53 \mathrm{mg}$ CE/100 g) reported by Tanvir et al. (2015). The Total flavonoids content of studied fruits was increased upon irradiation compared to nonirradiated control sample (Figure 5). The sample which received1.0 kGy gamma radiation also showed significant increase of flavonoid content compared to other treated samples. The increase pattern can be attributed to the phenylalanine ammonia lyase (PAL) activity, which is one of the key enzymes in the synthesis of flavonoids compounds in plant (Frohnmeyer and Staiger, 2003; Gitz et al., 2004). Cheng et al. (2005) also reported that the PAL directly induces flavonoid formation. In another study, Moghaddam et al. (2011) also reported the activity of PAL affects the flavonoid synthesis in Centella asiatica in response to gamma and UV-B irradiation. The flavonoid content in the $1.0 \mathrm{kGy}$ and $1.5 \mathrm{kGy}$ treated samples were significantly higher even after 8 days of storage than that of initial concentration of the untreated control samples.

The ascorbic acid content of studied jujube fruits is shown in the Figure 6. The initial value of ascorbic acid in fresh non-irradiated BAU Kul fruit was $10.77 \pm 1.43 \mathrm{mg} / 100 \mathrm{~g}$. In this study, ascorbic acid concentration decreased with the increase of radiation dose. In storage, reduced amount of ascorbic acid was observed in both radiation-treated and non-treated samples but radiation-treated samples showed less reduction. About 38\% reduction of ascorbic acid content was recorded in control sample whereas only $9.73 \%$ reduction was observed in case of $1.5 \mathrm{kGy}$ irradiated samples after 8 days of storage. Our findings corroborate with the findings of Owureku-Asare et al. (2014) who observed the decrease of vitamin $C$ content in both irradiated and non-irradiated samples over the storage period and found that irradiated samples retained higher vitamin $\mathrm{C}$ than control samples in pineapples (Ananas comosus). In another study, presence of similar level of vitamin $C$ was reported in citrus fruits which decreased with the increase of radiation doses and storage time (Ahmad et al., 2012). Dose-dependent decreases in total vitamin $\mathrm{C}$ content compared to control, both immediately after irradiation and after 5 and 10 days of storage was also observed in strawberries (Graham and Stevenson, 1997). Ascorbic acid is a heat sensitive bioactive compound and degraded by oxidative processes. Therefore, oxidation of ascorbic acid might be one of the causes of the observed decrease of the ascorbic acid content (Mohammad et al., 2009).

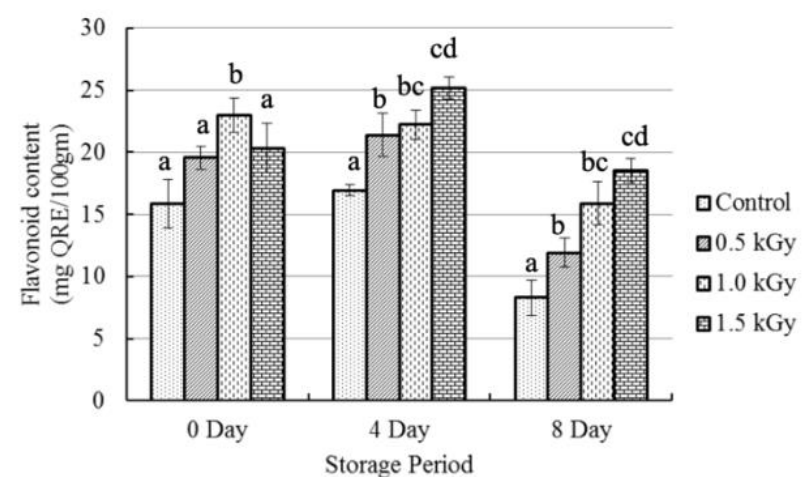

Figure 5. Effect of gamma irradiation doses on total flavonoid content of BAU Kul during storage at room temperature. Bars with different lowercase letters differ significantly $(p<0.05)$.

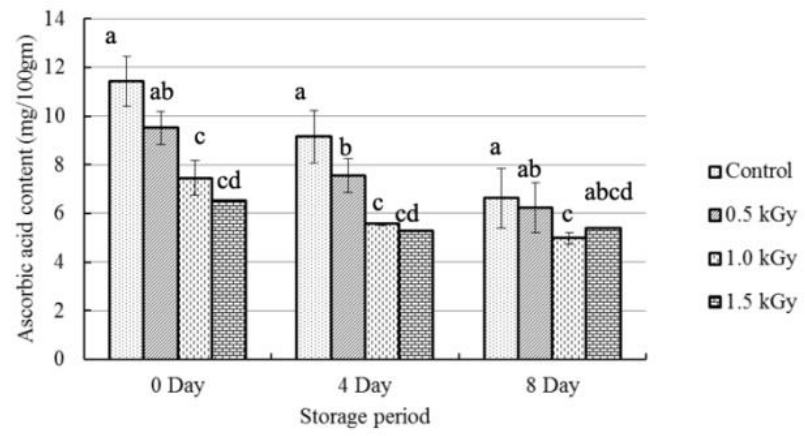

Figure 6. Effect of gamma irradiation doses on total ascorbic content of BAU Kul during storage at room temperature. Bars with different lowercase letters differ significantly $(p<0.05)$.

Sensory evaluation. Sensory evaluation of jujube fruits revealed that treated samples had more acceptability in terms of color, flavor, and texture up to 8 days of storage at ambient temperature compared to control (Table 2). Both irradiated and non-irradiated samples were good enough up to 4 days of observation. After 4 days, nonirradiated samples gradually lost its color, flavor and texture which ultimately lead to complete loss of acceptability within 8 days. This also corroborates with our findings that microbial counts increased significantly compared to that of initial counts in the non-irradiated jujube fruit samples. The overall acceptability of sample treated with $1.5 \mathrm{kGy}$ radiation was found 
significant $(p<0.05)$ in terms of all sensory attributes up to 8days compared to the control and the other irradiated samples. These results indicate that irradiation at $1.5 \mathrm{kGy}$ can improve the shelf life of jujube fruits without adverse effects on sensory attributes. Shelf life extension of strawberries, cherries, apricots and apple without affecting the sensory quality of the fruits was also achieved by the use of electron accelerators and gamma irradiation (Minea et al., 1996; Mridha et al., 2017).

Table 2. Sensory evaluation of jujube fruit treated with different doses of gamma irradiation during storage.

\begin{tabular}{ccccc}
\hline $\begin{array}{c}\text { Sensory } \\
\text { attributes }\end{array}$ & Treatments & 0 Day & 4 Day & $\mathbf{8}$ Day \\
\hline \multirow{3}{*}{ Color } & Control & $8.8^{\mathrm{a}}$ & $5.3^{\mathrm{a}}$ & $1.1^{\mathrm{a}}$ \\
& $0.5 \mathrm{kGy}$ & $8.9^{\mathrm{a}}$ & $5.5^{\mathrm{a}}$ & $3.3^{\mathrm{b}}$ \\
& $1.0 \mathrm{kGy}$ & $8.4^{\mathrm{a}}$ & $7.3^{\mathrm{b}}$ & $6.2^{\mathrm{c}}$ \\
& $1.5 \mathrm{kGy}$ & $8.7^{\mathrm{a}}$ & $7.7^{\mathrm{b}}$ & $1.4^{\mathrm{a}}$ \\
\hline \multirow{2}{*}{ Texture } & Control & $8.8^{\mathrm{a}}$ & $6.2^{\mathrm{a}}$ & $4.1^{\mathrm{b}}$ \\
& $0.5 \mathrm{kGy}$ & $8.8^{\mathrm{a}}$ & $6.2^{\mathrm{a}}$ & $5.9^{\mathrm{b}}$ \\
& $1.0 \mathrm{kGy}$ & $8.8^{\mathrm{a}}$ & $6.9^{\mathrm{a}}$ & $6.9^{\mathrm{c}}$ \\
\hline \multirow{3}{*}{ Flavor } & $1.5 \mathrm{kGy}$ & $8.5^{\mathrm{a}}$ & $7.2^{\mathrm{b}}$ & $2.0^{\mathrm{a}}$ \\
& Control & $8.8^{\mathrm{a}}$ & $6.6^{\mathrm{a}}$ & $6.2^{\mathrm{b}}$ \\
\hline \multirow{2}{*}{ Overall } & $0.5 \mathrm{kGy}$ & $8.6^{\mathrm{a}}$ & $6.9^{\mathrm{a}}$ & $7.5^{\mathrm{d}}$ \\
\hline acceptability & $1.0 \mathrm{kGy}$ & $8.4^{\mathrm{a}}$ & $7.4^{\mathrm{b}}$ & $1.5^{\mathrm{a}}$ \\
& $1.5 \mathrm{kGy}$ & $8.8^{\mathrm{a}}$ & $7.6^{\mathrm{b}}$ & $3.8^{\mathrm{b}}$ \\
& Control & $8.8^{\mathrm{a}}$ & $6.1^{\mathrm{a}}$ & $6.1^{\mathrm{c}}$ \\
\hline & $0.5 \mathrm{kGy}$ & $8.6^{\mathrm{a}}$ & $6.4^{\mathrm{a}}$ & $7.1^{\mathrm{d}}$ \\
\hline
\end{tabular}

Values are the average of 5 replicates. Values with different lowercase letters in column of each attributes differ significantly $(p<0.05)$.

\section{CONCLUSION}

This is the first report on the effects of gamma irradiation on the physico-chemical and microbiological attributes of BAU Kul variety of jujube. Briefly, findings of the present study demonstrate that gamma irradiation can be used as an effective technology to improve microbial quality, increase phenolics and flavonoids contents and extend shelf life of jujube fruit (cv. BAU Kul). Gamma irradiation might be useful to extend shelf life and reduce post harvest losses of other perishable fruits.

\section{ACKNOWLEDGEMENT}

The authors are grateful to Gamma Source Division for providing irradiation facilities and to the technical personnel for their support.

\section{REFERENCES}

Ahmad, I., Rahman, M., Rahman, M. M., Alam, M. M. M., \& Hussain, M. S. 2012. Effect of gamma radiation on the titrable acidity and vitamin $\mathrm{C}$ content of citrus fruits. International Journal of Agricultural Research Innovation and Technology 2(1): 1-6.

AOAC (Association of Official Analytical Chemists). 1975. Official methods of analysis (12 $2^{\text {th }}$ ed.), Washington DC.

Beltagi, H. S. E., Ahmed, O. K. A., \& El-Desouky, W. 2011. Effect of low doses $\gamma$-irradiation on oxidative stress and secondary metabolites production of rosemary (Rosmarinus officinalis $\mathrm{L}$.) callus culture. Radiation Physics and Chemistry 80: 968-976. 
Cappuccino, J. G. \& Sherman, N. 1996. Microbiology A Laboratory Manual, 4th ed. California, The Benjamin Cummings Publishing Co.

Chang, C., Yang, M., Wen, H., \& Chern, J. 2002. Estimation of total flavonoid content in propolis by two complementary colorimetric methods. Journal of Food and Drug Analysis 10 (3): 178-182.

Cheng, S. Y., Wang, Y., Liu, W. H., Du, H. W., \& Chen, K. S. 2005. Effects of plant growth regulators on phenylalanine ammonia-lyase (PAL) activities in leaves of Ginkgo biloba. Journal of Plant Resources and Environment 14: 20-22.

D’amour, J., Gosselin, C., Arul, J., Castaigne, F., \& Willemot, C. 1993. Gamma radiation affects cell wall composition of strawberries. Journal of Food Science 58(1): 182-185.

Ezz, Thanaa, M., Yousif, A. M., \& Farag, M. E. 2011. Morphological, physiological and biochemical genetic studies on some Indian jujube (Ziziphus mauritiana Lamk.). Egyptian Journal of Agricultural Research 89(4): 1499-1525.

Farkas, J. \& Mohácsi C. 2011. History and future of food irradiation. Food Science and Technology 22: 121-128.

Frohnmeyer, H. \& Staiger, D. 2003. Ultraviolet-B radiationmediated responses in plants. Balancing damage and protection. Plant Physiology 133: 1420-1428.

Geldof, N. \& Engeseth, N. J. 2002. Antioxidant capacity of honeys from various floral sources based on the determination of oxygen radical absorbance capacity and inhibition of in vitro lipoprotein oxidation in human serum samples. Journal of Agricultural and Food Chemistry 50: 3050-3055.

Gitz, D. C., Liu-Gitz, L., McClure, J. W., \& Huerta, A. J. 2004. Effects of a PAL inhibitor on phenolic accumulation and UV-B tolerance in Spirodela intermedia (Koch). Journal of Experimental Botany 55: 919-927.

Golding, J. B., Blades, B. L., Satyan, S., Spohr, L. J., Harris, A., Jassup, A. J., Archer, J. R., Davies, J. B., \& Banos, C. 2015. Low dose gamma irradiation does not affect the quality or total ascorbic acid concentration of "sweetheart" passion fruit (Passiflora edulis). Foods 4: 376-390.

Graham, W. D. \& Stevenson, M. H. 1997. Effect of irradiation on vitamin $\mathrm{C}$ content of strawberries and potatoes in combination with storage and with further cooking in potatoes. Journal of the Science of Food and Agriculture 75: 371377.

GSO (GCC Standardization Organization). 2014. Microbiological criteria for foodstuffs. Standardization Organization for Gulf Cooperation Council (GCC) Technical reports. GSO/FDS 1016/2014.

Hoque, M. Z., Akanda, A. M., Mia, I. H., Bhuiyan, K. A., Miah, M. G., \& Begum, F. 2016. Occurrence of fungal pathogens on improved jujube in Bangladesh. Fundamental and Applied Agriculture 1(3): 130-135.

IAEA (International Atomic Energy Agency).1977. Manual of food irradiation dosimetry, Technical Reports Series No. 178, IAEA, Vienna.

ICMSF (International Commission on Microbiological Specifications for Food). 1978. Microorganisms in Food. Their significance and methods for enumeration. 2nd ed. Toranto, University of Toranto press.

ICGFI (International Consultative Group on Food Irradiation), 1998. Safeguarding our harvests, assessing the use of irradiation in facilitating the achievement of food security goals in developing countries. Vienna: Joint FAO/IAEA Division of Nuclear Techniques in Food and Agriculture.

Iqtedar, M., Amjad, H., Sarwar, U., Asim, R., Kaleem, A., Abdullah, R., Aftab, M., Iftikhar, T., \& Naz, S. 2016. Effect of gamma radiation on microbial flora and shelf life of Malus domestica Borkh. International Journal of Biosciences 9(3): 47-52.
Karuppusamy, S., Muthuraja, G., \& Rajasekaran, K. M. 2011. Antioxidant activity of selected lesser known edible fruits from western ghats of India. Indian Journal of Natural Products and Resources 22: 174-178.

Khatun, A., Hossain, A., Islam, M., Hossain, A., Munshi, K., \& Huque, R. 2012. Effect of gamma radiation on antioxidant marker and microbial safety of fresh bitter gourd (Momordica charantia L.). International Journal of Biosciences 2 (11): 43-49.

Koley, T. K., Kaur, C., Nagal, S., Walla, S., Jaggi, S., \& Sarika, J. 2011. Antioxidant activity and phenolic content in genotypes of Indian jujube (Ziziphus mauritiana Lamk.). Arabian Journal of Chemistry 4: 1-9.

Krum, J. K. 1955). Truest evaluation in sensory panel testing. Journal of Food Engineering 27: 74-78.

Kume, T., Furuta, M., Todoriki, S., Uenoyama, N., \& Kobayashi, Y. 2009. Status of food irradiation in the world. Radiation Physics and Chemistry 78: 222-226.

Li, J. W., Fan, L. P., Ding, S. D., \& Ding, X. L. 2007. Nutritional composition of five cultivars of Chinese jujube. Food Chemistry 103(2): 454-460.

Majeed, A., Muhammad, Z., Majid, A., Shah, A. H., Hussain, M. 2014. Impact of low doses of gamma radiation on shelf life and chemical quality of strawberry (Fragaria $x$ ananassa) $\mathrm{cv}$. Corona. The Journal of Animal \& Plant Sciences 24(5): 15311536.

Minea, R., Oproiu, C., Pascanu, S., Matei, C., \& Ferdes, D. 1996. Preliminary research concerning the use of electron accelerators to improve the conservability and to extend the shelf-life of fruits and vegetables. Nuclear Instruments and Methods in Physics Research 113: 99-102.

Moghaddam, S. S., Jaffar, H. Z., Ibrahim, R., \& Rahmat, A. 2011. Effects of acute gamma irradiation on physiological traits and flavonoid accumulation of Centella asiatica. Molecules 16: 4994-5007.

Mohammad, A., Bhat, R., \& Karim, A. A. 2009. UV radiationinduced changes of antioxidant capacity of fresh-cut tropical fruits. Innovative Food Science and Emerging Technologies 10: $512-516$.

Mridha, F., Huque, R., Khatun, A., Islam, M., Hossain, A., Hossain, A., \& Kabir, M. S. 2017. Effects of gamma irradiation on antioxidant markers, microbial population and sensory attributes of Strawberry (Fragaria $\times$ ananassa Dutch.) cv. Festival. Plant Cell Biotechnology and. Molecular Biology 18(5 \&6): 208-218.

Oliveira, M., Pereira, J., Verde, S. C., Lima, M. J., Pinto, P., de Oliveira, P. B., Junqueira, C., Marcos, H., Silva, T., Melo, T., Santos, C. N., \& Botelho, M. L. 2013. Evaluation of potentiality of gamma radiation as a conservation treatment for blackberry fruits. Journal of Berry Research 3: 93-102.

Owureku-Asare, M., Adu-Gyamfi, A., Agyei-Amponsah, J., Agbemavor, W. S. K., Adom-Mensah, J. B., Acquah, S., Quayson, E., \& Saalia. F. 2014. Effect of gamma irradiation treatment and storage on physico-chemical, microbial and sensory quality of minimally processed pineapple (Ananas comosus). British Journal of Applied Science and Technology 4(19): 2752-2761

Ranganna, S. 1986. Handbook of Analysis and Quality Control for Fruit and Vegetable Products (2nd ed.). pp. 123-126. New Delhi, Tata McGraw-Hill.

Shena, X., Tanga, Y., Yangb, R., Yua, L., Fanga, T., \& Duan, J. A. 2009. The protective effect of Ziziphus jujube fruit on carbon tetrachloride induced hepatic injury in mice by antioxidative activities. Journal of Ethnopharmacology 122: 555-560.

Shibata, M., Yamatake, M., Sakamoto, M., Kanamori, K., \& Takagi, K. 1975. Pharmacological studies on bamboo grass. Nippon YakurigakuZassi 71: 481-490. 
Singleton, V. L. \& Rossi, J. A. 1965. Colorimetry of total phenolics with phosphomolybdic-phosphotungstic acid reagents. American Journal of Enology and Viticulture 16: 144-158.

Song, H., Kim, D., Jo, C., Lee, C., Kim, K., \& Byun, W. 2006. Effects of gamma irradiation on the microbiological quality and antioxidant activity of fresh vegetable juice. Food Microbiology 23: 372-378.

Talukdar, M. I., Rahman, S. S., Akhtaruzzaman, M., \& Samad, M. A. 2014. A comparative study on the nutritional quality of 5 (five) varieties of Bangladeshi jujubes (Zisyphus mauritiana). American Journal of Nutrition and Food Sciences 1(2): 32-36.

Tanvir, E. M., Afroz, R., Karim, N., Mottalib, M. A., Hossain, M. I., Islam, A., Gan, S. H., \& Khalil, I. 2015. Antioxidant and antibacterial activities of methanolic extract of BAU kul (Zisyphus mauritiana), an improved variety of fruit from Bangladesh. Journal of Food Biochemistry 39: 139-147.

Uddin, M. B. \& Hussain, I. 2012. Development of diversified technology for jujube (Ziziphus jujuba L.) processing and preservation. World Journal of Dairy \& Food sciences 7(1): 7478

Verde, S. C., Trigo, M. J., Sousa, M. B., Ferreira, A., Ramos, A. C., \& Nunes, I. 2013. Effects of gamma radiation on raspberries: Safety and quality issues. Journal of Toxicology and Environmental Health 76(4-5): 291-303.

Villavicencio, A. L. C. H., Mancini-Filho, J., Delincee, H., \& Greiner, R. 2000. Effect of irradiation on anti-nutrients (total phenolics, tannins and phytate) in Brazilian beans. Radiation Physics and Chemistry 57: 289-293.

WHO (World Health Organization). 1981. Wholesomeness of irradiated food. Technical reports series No. 659, World Health Organization, Geneva. 